\title{
Electrophysiological Evidence of Early Functional Damage in Glaucoma and Ocular Hypertension
}

\author{
Rachel V. North, Adrian L. Jones, Neville Drasdo, John M. Wild, and James E. Morgan
}

Purpose. The quantification of early retinal ganglion cell damage in ocular hypertension and glaucoma.

METHoDs. Thirty subjects under treatment for open-angle glaucoma, 23 subjects with ocular hypertension, and 28 healthy subjects in a control group were investigated by monocular pattern electroretinogram (ERG), L\&M (long and medium wavelength) cone ERG, and S (short wavelength)-cone ERG. The diagnosis of glaucoma was based on masked assessment of digital stereoscopic optic nerve head images by three glaucoma specialists. The optic nerve head and retinal nerve fiber layer was assessed by scanning laser ophthalmoscopy and optical coherence tomography.

RESUlts. All types of ERG had reduced mean amplitudes in ocular hypertension and open-angle glaucoma groups compared with the control group. In the ocular hypertension group, the N95 and the L\&M-pathway photopic negative response (PhNR) were significantly attenuated (by $19 \%$ and $18 \%$ compared with the control group, respectively; by $30 \%$ and $22 \%$, respectively, in the open-angle glaucoma group compared with the control group). In the subjects with open-angle glaucoma, the pattern ERG P50-N95 was found to be the most sensitive electrophysiological test, and the cup-disc area ratio, when examined by scanning laser ophthalmoscopy, was the most sensitive imaging parameter. Modest but not statistically significant correlations were found between the imaging and electrophysiologic parameters.

Conclusions. With disc appearance used for the classification of open-angle glaucoma and ocular hypertension, significant electrophysiological losses were found in both conditions. The modest correlation between the structural and electrophysiological measures suggests that these assess different aspects of the pathologic process; electrophysiology can be used to quantify retinal ganglion cell dysfunction that occurs before cell death. (Invest Ophthalmol Vis Sci. 2010;51:1216-1222) DOI: 10.1167/iovs.09-3409

$\mathrm{T}$ here is now compelling evidence that, in glaucoma, retinal ganglion cells undergo a prolonged period of dysfunction and degeneration before cell loss. ${ }^{1-5}$ These changes are manifested structurally as remodeling and pruning of the dendritic tree $e^{1,3,4}$ and functionally as a reduction in neuronal sensitivity. ${ }^{2-6}$ On their own, these changes would generate a discrepancy in clinical measures of the relationship between visual field loss and changes in retinal structure similar to those

From the School of Optometry and Vision Sciences, Cardiff University, Cardiff, Wales, United Kingdom.

Submitted for publication January 14, 2009; revised June 21 and August 21, 2009; accepted September 13, 2009.

Disclosure: R.V. North, None; A.L. Jones, None; N. Drasdo, None; J.M. Wild, None; J.E. Morgan, None

Corresponding author: Rachel V. North, School of Optometry and Vision Sciences, Cardiff University, Maindy Road, Cardiff CF24 4LU, UK; north@cardiff.ac.uk. reported..$^{7-10}$ Electrophysiological measurements from retinal ganglion cells in experimental glaucoma show reduced responsivity in both the spatial and temporal domains. ${ }^{2}$ It is likely therefore that these changes underlie the reduction in sensitivity in glaucoma, but further confirmatory work is needed.

Studies have shown that neuroretinal rim loss occurs before visual field loss ${ }^{7-10}$ and that visual field loss correlates better with ganglion cell loss in the more advanced stages of glaucoma. ${ }^{10}$ One explanation for the apparent nonlinear relationship between structure and function is that it is an artifact resulting from the logarithmic (decibel) scaling of the visual field. A linear relationship is found between the $1 /$ lambert differential light threshold and the temporal neuroretinal rim area. ${ }^{11}$ These observations do not exclude the possibility that reductions in sensitivity also reflect cell dysfunction as well as cell loss, ${ }^{2,4}$ which would imply a discrepancy between structure and function.

The discrepancies between clinical measures of structure and function depend on the particular measures being compared and their sensitivity and specificity. It would be expected that at the molecular level, the structure and function would be highly correlated. Therefore, with higher-resolution tools and comparable scales of structure and function a perfect correlation may be achieved.

We reasoned that a more sensitive measure of retinal ganglion cell integrity would be provided by electrophysiological measures of retinal ganglion cell function (pattern electroretinogram; PERG), ${ }^{12-27}$ photopic negative response $(\mathrm{PhNR})^{28-32}$ ) compared with other functional (perimetric) or structural measures. If this is the case, we would expect to find reductions in electrophysiological responses in eyes that are predisposed to retinal ganglion cell loss and in eyes with early structural damage, but with little in the way of visual field loss. We have used complimentary measures of retinal ganglion cell function (PERG, L\&M [long and medium wavelength]- and S [short wavelength]-pathway PhNR). Although these measures are sensitive indicators of neural damage, they relate to different pathways and to different areas of the retina. We included an assessment of the integrity of the S-pathway in view of the reported sensitivity to glaucoma. ${ }^{31,33-36}$

In this study, we tested the hypothesis that electrophysiological defects are present in the retina in patients with early structural damage and little or no perimetric loss. Data in support of this would be consistent with a sequence of retinal ganglion cell damage similar to that reported in experimental models of glaucoma.

\section{METHODS}

Healthy control subjects and patients with early stages of open-angle glaucoma and ocular hypertension (OHT) were recruited. The study adhered to the tenets of the Declaration of Helsinki and was approved by the BroTaf Health Authority (Wales, UK). All subjects gave informed consent. 


\section{Patients with Open-Angle Glaucoma and OHT}

Patients were recruited from the eye clinics at the University Hospital of Wales (Cardiff, UK). All patients underwent a routine clinical examination including optic nerve head assessment by slit lamp binocular indirect ophthalmoscopy, gonioscopy, perimetry (Humphrey Field Analyzer, Program 24-2 and SITA Fast Algorithm), and Goldmann applanation tonometry. Intraocular pressure measures were not corrected for corneal thickness. Stereophotographs of the optic nerve head were obtained with a stereoscopic fundus camera (3Dx; Nidek Inc., Pasadena, CA). All patients had normal color vision (Ishihara plates) and visual acuity of 20/30 or better in both eyes. Exclusion criteria were history of ocular (including refractive) surgery, other ocular diseases, use of systemic steroids or $\beta$-blockers, and a mean deviation (MD) greater than $-6 \mathrm{~dB}$. All participants in the study were in good general health. One eye was included in the study, and the nondominant eye was chosen if both eyes were eligible.

Digitized disc images of all participants were viewed stereoscopically with an IBM-compatible computer with a quad-buffered display and $Z$-screen (Stereographics Corp., San Rafael, CA). The optic nerve head status of each subject was assessed in a masked fashion by a panel of three ophthalmologists trained to fellowship standard in glaucoma (with agreement defined as two of three). The subjective assessment was based on standard clinical criteria for the diagnosis of glaucomatous damage, which included the presence of vertical saucerization, focal thinning (notching), and vertical asymmetry of the neuroretinal rim, loss of physiological rim shape, disc margin hemorrhage(s), and peripapillary atrophy. ${ }^{37}$ Classification of the subjects was made according to the stereoscopic optic nerve head images and untreated intraocular pressure. Subjects were grouped in the following manner: (1) open-angle glaucoma if glaucomatous optic neuropathy was present and the untreated IOP was $>21 \mathrm{~mm} \mathrm{Hg}$; (2) ocular hypertensive if the optic nerve head appeared healthy and the untreated IOP was $>21 \mathrm{~mm}$ $\mathrm{Hg}$ (on at least two consecutive occasions); and (3) control if the optic nerve head appeared healthy and the IOP $<21 \mathrm{~mm} \mathrm{Hg}$.

\section{Healthy Subjects}

An age-matched group of healthy subjects was recruited from friends or spouses of the patients attending the hospital and staff at Cardiff University. Inclusion criteria were visual acuity of 20/30 or better, intraocular pressure of less than $21 \mathrm{~mm} \mathrm{Hg}$, no ophthalmic disease, and no family history of glaucoma in a first-degree relative. Perimetric status was examined (Humphrey Field Analyzer, Program 24-2 and the SITA Fast algorithm; Carl Zeiss Meditec, Inc.). All subjects had undergone perimetry on at least one occasion. One eye was included in the study; the nondominant eye was chosen if both eyes were eligible.

\section{Electroretinography}

PERGs and ERGs were recorded monocularly. DTL electrodes were placed in the lower fornix and a 9-mm silver electrode placed close to the outer canthus for an ipsilateral temporal reference. A silver electrode at the midfrontal position, served as the ground. The unstimulated eye was patched throughout the recordings. PERGs were recorded with a 19-minute black-and-white checkerboard pattern stimulus, reversing four times per second (square wave reversal) at a $95 \%$ contrast. The stimuli were generated on a monitor subtending $24^{\circ}$ $\times 16^{\circ}$ at a viewing distance of $80 \mathrm{~cm}$. The stimuli covered the whole screen, which was $35-\mathrm{cm}$ wide and $27-\mathrm{cm}$ high. ${ }^{31}$ Each patient was refracted and viewed the checkerboard with an appropriately adjusted refractive correction. The pupil was then dilated to a minimum diameter of $7 \mathrm{~mm}$ with $2.5 \%$ phenylephrine and either $0.5 \%$ or $1 \%$ tropicamide. The L\&M-pathway ERG was recorded to a 5-ms flash of red light $(650 \mathrm{~nm})$ at $50 \mathrm{~cd} \cdot \mathrm{m}^{-2}$ on a continuous blue background $(450 \mathrm{~nm})$ at $2.7 \mathrm{~cd} \cdot \mathrm{m}^{-2}(>2000$ scotopic trolands), with a miniature Ganzfeld stimulator containing colored LEDs. ${ }^{31}$ The responses were recorded at a frequency of $1.8 \mathrm{~Hz}$. The S-pathway ERG was recorded with a silent substitution technique. ${ }^{31}$ To achieve photometric balance, blue light $\left(450 \mathrm{~nm}, 24 \mathrm{~cd} \cdot \mathrm{m}^{-2}\right)$ and green $(535 \mathrm{~nm})$ light were superimposed and flickered at $33 \mathrm{~Hz}$ on a red $(650 \mathrm{~nm})$ continuous background. The luminance of the green light was then adjusted until the patient no longer perceived the flicker. At this frequency, rods and S-cones do not contribute significantly, and the balance is presumed to correct for the M-cones. When the frequency is reduced to $1.67 \mathrm{~Hz}$, the S-cones respond, and the M-cones remain silent. The L-cone response is suppressed by the continuous red background at $108 \mathrm{~cd} \cdot \mathrm{m}^{-2}$ and the rod response is saturated at the intensities used ( $>2000$ scotopic trolands).

\section{Optic Nerve Head Imaging}

The OCT uses low-coherence interferometry to provide measures of retinal thickness. Three circular scans with a radius of $1.74 \mathrm{~mm}$ centered on the midpoint of the optic nerve head were acquired by OCT (Humphrey OCT Model 2000 with software version A5.0; Carl Zeiss Meditec, Inc.). ${ }^{38}$ The OCT provides 100 axial scans along the scan profile line, and the image acquisition was achieved in approximately 1 second per scan. An arbitrarily color-coded image is generated from which estimates of the global retinal nerve fiber layer (RNFL) and the global full retinal thickness (FRT) are made by proprietary algorithms. Global measures are the average of the 100 points along each circular scan.

Three $10^{\circ}$ images centered on the optic disc were acquired (Heidelberg Retina Tomograph [HRT]; Heidelberg GmbH, Heidelberg, Germany). ${ }^{39}$ The HRT uses a 670-nm wavelength diode laser and a confocal imaging system to provide topographic measures of the optic nerve head and peripapillary retina. The acquisition time for each image was approximately 1.67 seconds. Off-line, the HRT software aligned the three images and created a mean topographic image for further analysis. A contour line was then manually placed along the optic nerve head margin as defined by the location of Elschnig's ring. From this, topographic parameters including the disc area; cup depth, area and volume; neural retinal rim area; and RNFL thickness were calculated (HRT software version 2.01b; Heidelberg Engineering) according to the standard reference plane by a research optometrist (AJ). All these parameters provide information about the disc structure and take into account the three-dimensional shape of the neuroretinal rim and optic cup.

\section{Data Analysis and Statistics}

All electrophysiology traces were characterized by two negative and one positive deflection in the order N1, P1, and N2 (Fig. 1). The PERG $\mathrm{P} 50$ was measured from $\mathrm{N} 1$ to $\mathrm{P} 1$, the $\mathrm{P} 50-\mathrm{N} 95$ from $\mathrm{P} 1$ to $\mathrm{N} 2$, and the N95 from baseline. The a-wave (N1) of the L\&M- and S-pathway ERGs was measured from the baseline, the b-wave (P1) from baseline, and the PhNR from baseline to N2 and also from P1 to N2 (peak to peak). Between-subject group comparisons were made with either the Student's $t$-test or the Mann-Whitney $\mathrm{U}$ test, depending on the distribution of the data. A receiver operating characteristic (ROC) analysis was performed for each test to determine the area under the ROC curve (SPSS V11.0 software; SPSS Inc., Chicago, IL).

\section{Results}

Subject characteristics are shown in Table 1 with all subjects classified as open-angle glaucoma, OHT, or control, according to optic nerve head appearance and untreated IOP. The openangle glaucoma group comprised 30 subjects ( 14 men and 16 women); the OHT group, 23 subjects (13 men and 10 women); and the control group, 28 subjects (12 men and 16 women).

All subjects in the open-angle glaucoma group and 11 of the OHT subjects were receiving oculohypotensive therapy. Compared with the control group, the IOP was significantly higher in the open-angle glaucoma and OHT groups and the visual field indices were significantly different in the open-angle glaucoma group. 


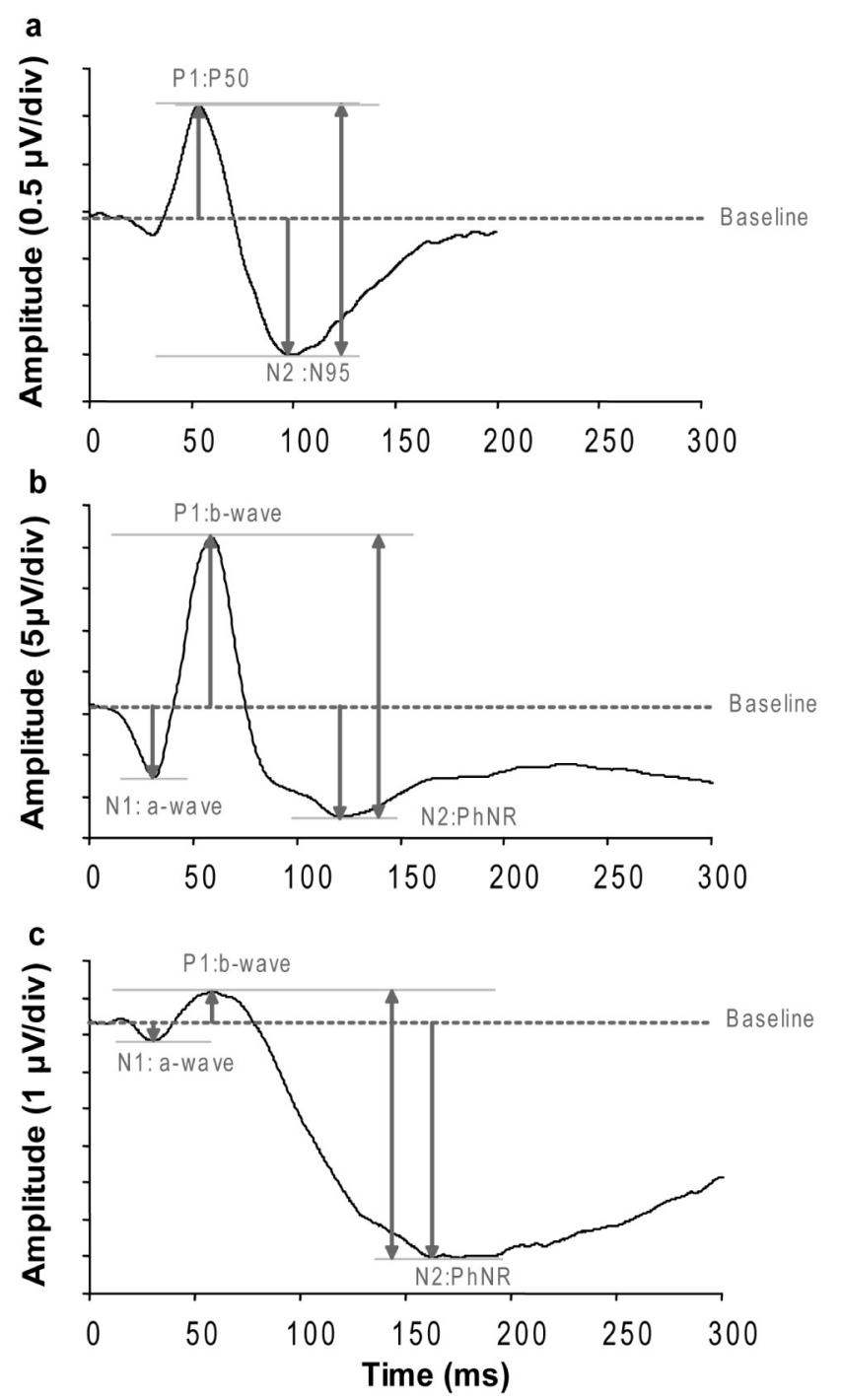

FIGURE 1. Examples of electrophysiological traces for (a) PERG, (b) L\&M-cone ERG, and (c) S-cone ERG.

\section{Electrophysiology}

ERG amplitudes are summarized in Table 2. There were no significant differences in the implicit times of the various ERG components for either the open-angle glaucoma or OHT groups compared with the control subjects, and therefore they have not been included. Both groups showed reduced amplitudes for each ERG when compared to the control group.
Pattern ERG. The N95 amplitude was significantly reduction in the OHT group, but the P50-N95 provided slightly better discrimination from the controls with an ROC area of 0.70 .The open-angle glaucoma subjects showed significantly smaller PERG amplitudes compared to the control subjects. Although there was similar attenuation of both the P50 and $\mathrm{N} 95$, the P50-N95 amplitude provided the best discrimination between the groups with an ROC area score of 0.79 . The ROC area varied between 0.70 and 0.79 and 0.63 and 0.70 for the various electrophysiological parameters of the open-angle glaucoma and OHT group, respectively.

L\&M-Pathway. The PhNR from the L\&M-pathway ERG was significantly reduced in both groups. The b-wave was also significantly reduced in the open-angle glaucoma group. The ROC area varied between 0.63 and 0.75 and 0.57 and 0.71 for the various electrophysiological parameters in the open-angle glaucoma and OHT group, respectively.

S-Pathway. Of the S-pathway measures, the PhNR was the only statistically reduced parameter in the open-angle glaucoma group compared with the control subjects, with a modest ROC area score of 0.60 .

The ROC area varied from 0.56 to 0.61 and from 0.55 to 0.63 for the various electrophysiological parameters in the open-angle glaucoma and OHT group, respectively.

\section{Imaging}

A summary of the imaging data is shown in Table 3. All HRT parameters (except RNFL thickness, disc area) were significantly different between the open-angle glaucoma and the control group. No significant differences were found between any of the parameters of the OHT and control group. The OCT global RNFL thickness was significantly reduced in the openangle glaucoma group compared with the control group. Global FRT was significantly reduced in both the open-angle glaucoma and OHT group (Fig. 2).

\section{Effect of Oculohypotensive Treatment in OHT}

Of the 23 subjects with OHT, 11 subjects were being treated with pressure-lowering topical drops. The IOP was $24.81 \mathrm{~mm}$ $\mathrm{Hg}$ (SEM 0.78) and $19.17 \mathrm{~mm} \mathrm{Hg}$ (SEM 1.52) in the untreated and treated groups, respectively. There were no significant differences between the imaging parameters in either the treated or untreated group compared with the control group. None of the electrophysiological parameters was reduced in the treated group, but the PERG N95, P50-N95 and L\&Mpathway PhNR were significantly reduced in the untreated group compared with the control group (Table 4 ).

The correlation between the imaging and electrophysiological parameters are shown in Table 5. When ERG parameters were compared, the highest correlation found was between the PERG P50-N95 and the L\&M-pathway PhNR $(r=0.453$, $P=0.00002)$.

TABLE 1. Details of Sample Construction

\begin{tabular}{|c|c|c|c|c|c|c|}
\hline & \multicolumn{2}{|c|}{ Control $(n=28)$} & \multicolumn{2}{|c|}{$\begin{array}{l}\text { Open Angle Glaucoma } \\
\qquad(n=30)\end{array}$} & \multicolumn{2}{|c|}{$\begin{array}{l}\text { Ocular Hypertension } \\
\qquad(n=23)\end{array}$} \\
\hline & Mean & SEM & Mean & SEM & Mean & SEM \\
\hline Age, y & 59.36 & 1.70 & 60.70 & 1.82 & 60.17 & 1.68 \\
\hline Sphere, DS & +0.20 & 0.35 & +0.68 & 0.34 & -0.27 & 0.74 \\
\hline Cylinder, DC & -0.52 & 0.12 & -0.44 & 0.08 & -0.73 & 0.14 \\
\hline IOP, mm Hg & 14.20 & 0.28 & 19.87 & 0.33 & 22.11 & 0.41 \\
\hline $\mathrm{MD}, \mathrm{dB}$ & 0.14 & 0.12 & -1.89 & 0.36 & -0.85 & 0.16 \\
\hline PSD, $\mathrm{dB}$ & 1.81 & 0.12 & 3.39 & 0.88 & 1.97 & 1.01 \\
\hline
\end{tabular}

Bold data indicate a significant difference versus the control group $(P<0.05)$. 


\begin{tabular}{|c|c|c|c|c|c|c|c|c|c|c|c|c|}
\hline & \multicolumn{2}{|c|}{ Control } & \multicolumn{5}{|c|}{ Ocular Hypertension } & \multicolumn{5}{|c|}{ Open Angle Glaucoma } \\
\hline & Mean & SEM & Mean & SEM & $\begin{array}{c}\% \\
\text { Change }\end{array}$ & $\boldsymbol{P}$ & $\begin{array}{l}\text { ROC } \\
\text { Area }\end{array}$ & Mean & SEM & $\begin{array}{c}\% \\
\text { Change }\end{array}$ & $\boldsymbol{P}$ & $\begin{array}{l}\text { ROC } \\
\text { Area }\end{array}$ \\
\hline \multicolumn{13}{|l|}{ PERG } \\
\hline $\mathrm{P} 50, \mu \mathrm{V}$ & -1.95 & 0.19 & -1.55 & 0.16 & -21 & 0.118 & 0.628 & -1.38 & 0.13 & -29 & 0.014 & 0.685 \\
\hline $\mathrm{N} 95, \mu \mathrm{V}$ & 1.71 & 0.15 & 1.38 & 0.12 & -19 & 0.027 & 0.682 & 1.20 & 0.12 & -30 & 0.002 & 0.733 \\
\hline $\mathrm{P} 50-\mathrm{N} 95, \mu \mathrm{V}$ & 3.65 & 0.30 & 2.93 & 0.26 & -20 & 0.063 & 0.702 & 2.57 & 0.15 & -30 & 0.002 & 0.787 \\
\hline \multicolumn{13}{|l|}{ L\&M-pathway ERG } \\
\hline a-Wave, $\mu \mathrm{V}$ & 9.24 & 0.59 & 8.41 & 0.56 & -9 & 0.321 & 0.574 & 7.86 & 0.48 & -15 & 0.076 & 0.632 \\
\hline b-Wave, $\mu \mathrm{V}$ & -23.29 & 1.82 & -19.68 & 2.02 & -16 & 0.190 & 0.634 & -17.66 & 1.67 & -24 & 0.026 & 0.670 \\
\hline $\begin{array}{l}\mathrm{PhNR}, \mu \mathrm{V} \\
\quad \text { (baseline-trough) }\end{array}$ & 16.12 & 0.92 & 13.17 & 0.82 & -18 & 0.023 & 0.711 & 12.53 & 1.23 & -22 & 0.001 & 0.746 \\
\hline $\begin{array}{l}\text { PhNR, } \mu \mathrm{V} \text { (peak } \\
\text { to peak) }\end{array}$ & 39.42 & 2.50 & 32.85 & 2.66 & -17 & 0.079 & 0.655 & 30.19 & 2.02 & -23 & 0.006 & 0.725 \\
\hline \multicolumn{13}{|l|}{ S-pathway ERG } \\
\hline a-Wave, $\mu \mathrm{V}$ & 1.50 & 0.35 & 1.15 & 0.12 & -23 & 0.548 & 0.550 & 1.02 & 0.12 & -32 & 0.175 & 0.607 \\
\hline b-Wave, $\mu \mathrm{V}$ & -1.15 & 0.31 & -0.73 & 0.19 & -36 & 0.460 & 0.561 & -0.79 & 0.27 & -31 & 0.458 & 0.557 \\
\hline $\begin{array}{l}\mathrm{PhNR}, \mu \mathrm{V} \\
\quad \text { (baseline-trough) }\end{array}$ & 4.44 & 0.61 & 3.42 & 0.21 & -23 & 0.262 & 0.594 & 3.26 & 0.36 & -27 & 0.041 & 0.602 \\
\hline $\begin{array}{l}\text { PhNR, } \mu V \text { (peak } \\
\text { to peak) }\end{array}$ & 5.68 & 0.87 & 4.15 & 0.25 & -27 & 0.133 & 0.625 & 4.05 & 0.37 & -29 & 0.064 & 0.603 \\
\hline
\end{tabular}

Bold data indicate a significant difference versus the control group $(P<0.05)$. Change is in comparison with the control group.

\section{Discussion}

The major finding of our study is that there was a deficit in electrophysiological measurement of ganglion cell function in subjects with OHT. In addition, we found deficits in the bipolar and ganglion cell function in patients with early open-angle glaucoma with no or minimal visual field loss.

The mean amplitudes of all the electrophysiological parameters were reduced in both the OHT and open-angle glaucoma group compared with the control group. Of the 11 parameters measured, the majority $(7 / 11)$ were significantly reduced in the open-angle glaucoma group compared with those in the OHT group (2/11). In the OHT group, the N95 was the only significantly attenuated PERG parameter, with a $19 \%$ reduction compared with $30 \%$ in the open-angle glaucoma group. The L\&M-pathway PhNR was also significantly attenuated, being reduced by $18 \%$ compared with $22 \%$ in the open-angle group. A similar reduction of the PhNR amplitude has been reported by our group, using a long-duration flash $(200 \mathrm{~ms}) .{ }^{32}$ These findings are consistent with less damage or dysfunction in the OHT group than in the open-angle glaucoma group.

In the open-angle glaucoma group, the PERG P50-N95 amplitude was statistically the most affected electrophysiological parameter that provided the greatest discriminatory power. This result is not surprising, as the PERG has been shown to be sensitive to diffuse loss, and it has been hy-

TABLe 3. Imaging Parameters

\begin{tabular}{|c|c|c|c|c|c|c|c|c|c|c|c|c|}
\hline & \multicolumn{2}{|c|}{ Control } & \multicolumn{5}{|c|}{ Ocular Hypertensions } & \multicolumn{5}{|c|}{ Open-Angle Glaucoma } \\
\hline & Mean & SEM & Mean & SEM & $\begin{array}{c}\% \\
\text { Change }\end{array}$ & $\boldsymbol{P}$ & $\begin{array}{l}\text { ROC } \\
\text { Area }\end{array}$ & Mean & SEM & $\begin{array}{c}\% \\
\text { Change }\end{array}$ & $\boldsymbol{P}$ & $\begin{array}{l}\text { ROC } \\
\text { Area }\end{array}$ \\
\hline \multicolumn{13}{|l|}{ HRT } \\
\hline Disc area, $\mathrm{mm}^{2}$ & 1.90 & 0.10 & 1.79 & 0.06 & -6 & 0.583 & 0.455 & 1.89 & 0.07 & 0 & 0.565 & 0.544 \\
\hline Cup Area, $\mathrm{mm}^{2}$ & 0.50 & 0.09 & 0.49 & 0.05 & -3 & 0.364 & 0.575 & 0.95 & 0.07 & 89 & 0.000003 & 0.860 \\
\hline $\begin{array}{l}\text { Cup-disc area } \\
\text { ratio }\end{array}$ & 0.24 & 0.03 & 0.27 & 0.02 & 10 & 0.188 & 0.608 & 0.50 & 0.02 & 100 & 0.0000005 & 0.886 \\
\hline $\mathrm{NNR}$ area, $\mathrm{mm}^{2}$ & 1.35 & 0.09 & 1.22 & 0.09 & -10 & 0.318 & 0.551 & 0.94 & 0.05 & -30 & 0.0002 & 0.802 \\
\hline $\begin{array}{l}\text { Cup volume, } \\
\mathrm{mm}^{3}\end{array}$ & 0.11 & 0.03 & 0.09 & 0.02 & -20 & 0.670 & 0.535 & 0.31 & 0.05 & 177 & 0.000003 & 0.858 \\
\hline $\begin{array}{l}\text { NNR volume, } \\
\mathrm{mm}^{3}\end{array}$ & 0.35 & 0.03 & 0.35 & 0.03 & -2 & 0.879 & 0.552 & 0.24 & 0.03 & -32 & 0.0004 & 0.770 \\
\hline Cup depth, mm & 0.18 & 0.02 & 0.21 & 0.01 & 10 & 0.409 & 0.571 & 0.34 & 0.02 & 78 & 0.0000002 & 0.880 \\
\hline $\begin{array}{l}\text { Max cup depth, } \\
\text { mm }\end{array}$ & 0.52 & 0.04 & 0.56 & 0.4 & 7 & 0.496 & 0.547 & 0.75 & 0.03 & 43 & 0.00001 & 0.796 \\
\hline CSM & -0.20 & 0.20 & -0.17 & 0.01 & -14 & 0.068 & 0.650 & -0.09 & 0.01 & -55 & 0.000002 & 0.866 \\
\hline $\begin{array}{l}\text { RNFL thickness, } \\
\text { mm }\end{array}$ & 0.22 & 0.01 & 0.23 & 0.02 & 6 & 0.566 & 0.463 & 0.19 & 0.01 & -12 & 0.158 & 0.620 \\
\hline \multicolumn{13}{|l|}{ OCT } \\
\hline $\begin{array}{l}\text { Global RNFL } \\
\text { thickness, } \mu \mathrm{m}\end{array}$ & 122.42 & 2.44 & 116.25 & 2.31 & -5 & 0.076 & 0.649 & 104.66 & 3.44 & -15 & 0.0001 & 0.780 \\
\hline Global FRT, $\mu \mathrm{m}$ & 296.83 & 19.27 & 260.87 & 10.29 & -12 & 0.016 & 0.615 & 252.51 & 11.86 & -15 & 0.003 & 0.725 \\
\hline
\end{tabular}

Bold data indicate a significant difference versus the control group $(P<0.05)$ \% Change is in comparison with the control group. 


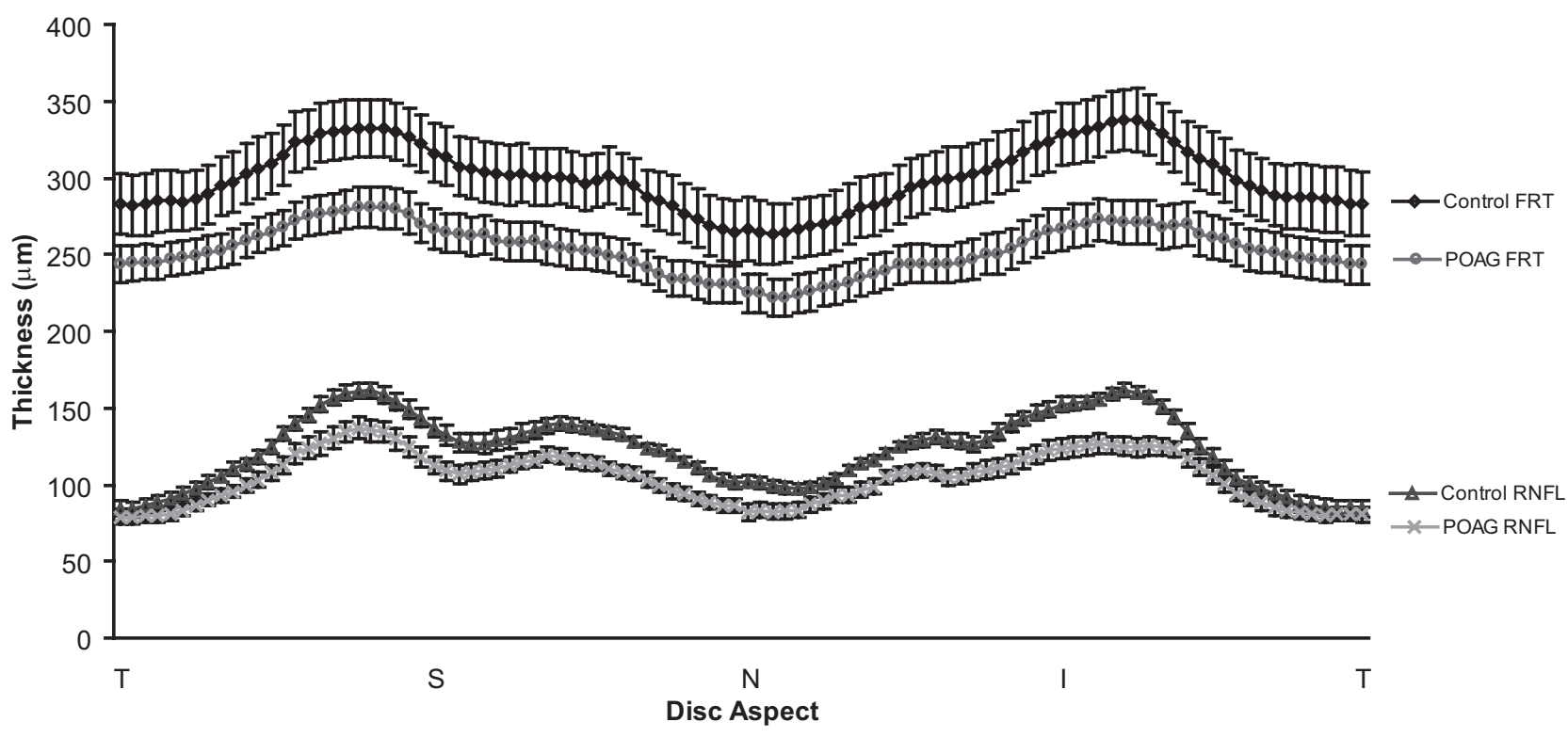

FIGURE 2. FRT and RNFL layer thickness measurements (mean and SEM) by OCT in the control and open-angle glaucoma group. T, temporal; S, superior; N, nasal; I, inferior disc location.

pothesized that open-angle glaucoma commences with a diffuse defect. ${ }^{40}$ Although other studies have shown higher discriminatory values, these differences may be explained by the more advanced nature of the glaucoma of the subjects who participated, with mean MDs being $-4.04 \mathrm{~dB}^{20}$ and $-3.22 \mathrm{~dB}^{32}$ compared with $-1.89 \mathrm{~dB}$ in the present study.

In agreement with previous studies, the most significantly affected flash ERG parameter was the PhNR of the brief-stimulus L\&M-pathway flash ERG. ${ }^{28,29}$ The significant attenuation of the L\&M-pathway ERG b-wave implies that there may damage to the bipolar cells in the distal retina. Further evidence of bipolar dysfunction is provided by the OCT measurements and a recent histologic analysis in human glaucoma reporting neuronal loss in the outer retinal layers. ${ }^{41}$ The b-wave deficits for the L\&M- and S-pathways are nearly identical with those of the PhNR. This finding is contrary to that of Viswanathan et al. ${ }^{29}$ who found that the b-wave was not significantly reduced in patients with open-angle glaucoma. However, similar deficits in these electrophysiological measures have been previously reported by our group ${ }^{31}$ and both studies have found the b-wave to be less sensitive than the PhNR in distinguishing healthy from glaucomatous eyes. This topic requires further investigation to understand the differences reported.

A significant reduction was found of both the RNFL thickness and the FRT (full retinal thickness) of the open-angle glaucoma group as measured by the OCT, the percentage difference in each parameter being approximately the same. There is some debate as to the accuracy of the OCT measurement of RNFL thickness. Compared with histologic measurements made from postmortem human eyes, ${ }^{42,43}$ the OCT consistently underestimates RNFL thickness. ${ }^{44}$ Nevertheless, our results imply a reduction of retinal thickness that may occur not only due to a loss of retinal ganglion cells and their axons, but also due to a loss of other retinal cells and/or their processes. There may be a loss of the somas in the retinal ganglion cell layer and thinning of the inner plexiform layer. In this

TABLE 4. ERG Parameters in Subjects with OHT According to Treatment Status

\begin{tabular}{|c|c|c|c|c|c|c|c|c|}
\hline & \multicolumn{2}{|c|}{ Treated OHT } & \multicolumn{2}{|c|}{ Untreated OHT } & \multicolumn{2}{|c|}{ Treated OHT } & \multicolumn{2}{|c|}{ Untreated OHT } \\
\hline & Mean & SEM & Mean & SEM & $\%$ Change & $\boldsymbol{P}$ & $\%$ Change & $\boldsymbol{P}$ \\
\hline \multicolumn{9}{|l|}{ PERG } \\
\hline $\mathrm{P} 50, \mu \mathrm{V}$ & -2.23 & 0.67 & -1.43 & 0.24 & -14 & 0.417 & -27 & 0.116 \\
\hline N95, $\mu \mathrm{V}$ & 1.56 & 0.75 & 1.22 & 0.10 & -9 & 0.532 & -29 & 0.004 \\
\hline P50-N95, $\mu \mathrm{V}$ & 2.50 & 0.24 & 2.64 & 0.28 & -11 & 0.425 & -28 & 0.047 \\
\hline \multicolumn{9}{|l|}{ L\&M-pathway ERG } \\
\hline a-Wave, $\mu \mathrm{V}$ & 9.60 & 0.73 & 7.32 & 0.73 & 4 & 0.731 & -21 & 0.068 \\
\hline b-Wave, $\mu \mathrm{V}$ & -22.03 & 3.35 & -17.53 & 2.31 & -5 & 0.726 & -25 & 0.077 \\
\hline $\mathrm{PhNR}, \mu \mathrm{V}$ (baseline-trough) & 14.01 & 1.48 & 12.40 & 0.80 & -13 & 0.231 & -23 & 0.018 \\
\hline PhNR, $\mu \mathrm{V}$ (peak to peak) & 36.04 & 4.52 & 29.93 & 2.91 & -9 & 0.493 & -24 & 0.033 \\
\hline \multicolumn{9}{|l|}{ S-pathway ERG } \\
\hline a-Wave, $\mu \mathrm{V}$ & 1.22 & 0.20 & 1.09 & 0.15 & -18 & 0.894 & -28 & 0.414 \\
\hline b-Wave, $\mu \mathrm{V}$ & -0.79 & 0.27 & -0.68 & 0.28 & -31 & 0.596 & -41 & 0.516 \\
\hline $\mathrm{PhNR}, \mu \mathrm{V}$ & 3.24 & 0.27 & 3.59 & 0.31 & -27 & 0.207 & -19 & 0.572 \\
\hline PhNR, $\mu \mathrm{V}$ (peak to peak) & 4.03 & 0.31 & 4.27 & 0.41 & -29 & 0.153 & -25 & 0.315 \\
\hline
\end{tabular}

Bold data indicate a significant difference versus the control group $(P<0.05)$ \% Change is in comparison with the control group. 
TABLE 5. Correlations of the Best Performing Imaging Parameters against ERG Parameters

\begin{tabular}{|c|c|c|c|c|c|c|}
\hline & \multicolumn{2}{|c|}{ PERG P50-N95 } & \multicolumn{2}{|c|}{ L\&M-Pathway PhNR } & \multicolumn{2}{|c|}{ S-Pathway PhNR } \\
\hline & $\boldsymbol{R}$ & $\boldsymbol{P}$ & $\boldsymbol{R}$ & $\boldsymbol{P}$ & $\boldsymbol{R}$ & $\boldsymbol{P}$ \\
\hline Cup area & -0.368 & 0.001 & -0.231 & 0.039 & -0.033 & 0.773 \\
\hline Cup-disc area ratio & -0.389 & 0.0003 & -0.259 & 0.020 & -0.075 & 0.551 \\
\hline NRR area & 0.190 & 0.089 & 0.358 & 0.001 & 0.179 & 0.115 \\
\hline Cup volume & -0.339 & 0.002 & -0.235 & 0.036 & 0.012 & 0.915 \\
\hline Cup depth & -0.272 & 0.014 & -0.257 & 0.021 & -0.053 & 0.645 \\
\hline CSM & -0.363 & 0.001 & -0.289 & 0.009 & -0.239 & 0.034 \\
\hline OCT RNFL thickness & 0.258 & 0.020 & 0.281 & 0.012 & 0.131 & 0.248 \\
\hline
\end{tabular}

Bold data indicate a significant correlation $(P<0.05)$.

study, we were primarily interested in the imaging of the RNFL of the peripapillary area; however, for more reliable measures of the retinal ganglion cell layer and other layers, the parafoveal area should also be imaged.

The S-pathway PhNR was reduced in open-angle glaucoma, which agrees with findings in other studies of S-cone dysfunction. ${ }^{31,33-35}$ This result suggests that the defects of the bluesensitive mechanism occur at a later stage of the disease process when ganglion cell death is present and is supported by the fact that SWAP (short-wavelength automated perimetry) results correlate with RNFL thickness measured by OCT in patients with glaucoma. ${ }^{45} \mathrm{~A}$ nonsignificant reduction was found for the $\mathrm{S}$ cone $\mathrm{b}$-wave and PhNR for the OHT group compared with the control group, contrary to the findings of our previous study. ${ }^{32}$ The reduction of the mean amplitudes for the b-wave and PhNR was $22 \%$ and $30 \%^{32}$ compared with $36 \%$ and $27 \%$, respectively.

The highly significant correlation of the PERG P50-N95 with the PhNR suggests a common origin for these potentials, which is in general agreement with previous studies. ${ }^{31,32,46}$ The highly significant correlations found between the imaging parameters, PERG amplitudes, and the L\&M-pathway PhNR imply a reproducible relationship between optic nerve head tomography and retinal function. However, the modest correlation coefficients ( $\max r=0.37$ ) suggest that this may not be a linear relationship. These findings of modest correlation coefficient in patients with OHT or early stages of glaucoma are in agreement with previous studies. ${ }^{47,48}$ Higher correlation coefficients $(r \geq 0.60)$ have been found in open-angle glaucoma with more advanced visual field loss. ${ }^{49,50}$

The lack of strong correlation coefficients found in our study ( $r<0.50$ for all) between the ERG and imaging parameters is not surprising. This weak correlation applied in particular to the subjects with OHT in whom attenuation of ERG amplitudes indicated depressed retinal function in the absence of significant changes in optic nerve head tomography (it is interesting to note that FRT was reduced). If these changes in retinal function were caused by ganglion cell dysfunction ${ }^{4}$ rather than cell death, then it is unlikely that optic nerve head changes would be apparent, since these changes can occur with preservation of the retinal ganglion cell axon. ${ }^{51}$ Our findings are consistent with a report that the reduction in retinal function (assessed by the PERG) for the central visual field exceeded that expected from loss of retinal ganglion cells (as assessed by OCT). ${ }^{52}$

Although our data are consistent with cell dysfunction, we cannot rule out retinal ganglion cell loss that is undetectable by HRT- and OCT-based structural measures. Since glial tissue can remodel in response to axon loss, it can provide an offset to any detectable reduction in RNFL thickness. ${ }^{53}$ The use of higher resolution imaging techniques such as ultrahigh resolution OCT may resolve this issue. ${ }^{54}$
An intriguing finding is that subjects with treated OHT did not show any difference in electrophysiological parameters when compared with control subjects. By contrast, patients with untreated OHT showed significant differences, as measured by PERG and PhNR. These observations raise the possibility that some of the deficits associated with OHT are reversible, and hence longitudinal studies in patients with OHT before and after treatment are needed for confirmation.

The highly significant correlation between ERG amplitudes and imaging parameters combined with only modest correlation coefficients supports the view that structural changes to the optic nerve head and the attenuation of ERG parameters are occurring at different points in the pathologic process. Our data are consistent with the hypothesis that retinal ganglion cell dysfunction occurs before retinal ganglion cell death.

\section{References}

1. Weber AJ, Kaufman PL, Hubbard WC. Morphology of single ganglion cells in the glaucomatous primate. Invest Opbthalmol Vis Sci. 1998;39:2304-2320.

2. Weber AJ, Harman, CD. Structure-function relations of parasol cells in the normal and glaucomatous primate retina. Invest $O p b$ thalmol Vis Sci. 2005;46:3197-3207.

3. Shou T, Liu J, Wang W, Zhou Y, Zhao K. Differential dendritic shrinkage of alpha and beta retinal ganglion cells in cats with chronic glaucoma. Invest Opbthalmol Vis Sci. 2003;44:30053010.

4. Morgan JE, Datta AV, Erichsen JT, Albon J, Boulton ME. Retinal ganglion cell remodelling in experimental glaucoma. Adv Exp Med Biol. 2006;572:397-402.

5. Buckingham BP, Inman DM, Lambert W, et al. Progressive ganglion cell degeneration precedes neuronal loss in a mouse model of glaucoma. J Neurosci. 2008;28(11):2735-2744.

6. Holcombe D, Lengefeld N, Gole GA, Barnett NL. Selective inner retinal dysfunction precedes ganglion cell loss in a mouse glaucoma model. Br J Ophthalmol. 2008;92(5):683-688.

7. Sommer A, Tielsch JM, Katz J, et al. Clinically detectable nerve fiber atrophy precedes the onset of glaucomatous field loss. Arch Opbthalmol. 1991;109:77-83.

8. Kamal DS, Viswanathan AC, Garway-Heath DF, et al. Detection of optic disc change with the Heidelberg retina tomograph before confirmed visual field change in ocular hypertensives converting to early glaucoma. Br J Opbthalmol. 1999;83:290-294.

9. Tuulonen A, Lehtola J, Airaksinen PJ. Nerve fiber layer defects with normal visual fields: do normal optic disc and normal visual field indicate absence of glaucomatous abnormality? Ophthalmology. 1993;100:587-597.

10. Harwerth RS, Carter-Dawson L, Shen F, et al. Ganglion cell losses underlying visual field defects from experimental glaucoma. Invest Ophthalmol Vis Sci. 1999;40:2242-2250.

11. Garway-Heath DF, Holder GE, Fitzke FW, et al. Relationship between electrophysiological, psychophysical and anatomical measures in glaucoma. Invest Ophthalmol Vis Sci. 2002;43:22132220. 
12. Holder GE. Significance of abnormal pattern electroretinography in anterior visual pathway dysfunction. Br J Ophthalmol. 1987; 71(3):166-171.

13. Weinstein GW, Arden GB, Hitchings RA, et al. The pattern electroretinogram (PERG) in ocular hypertension and glaucoma. Arch Ophthalmol. 1988;106:923-928.

14. Korth M. The value of electrophysiological testing in glaucomatous diseases. J Glaucoma. 1997;6:331-343.

15. Wanatabe I, Iijima $\mathrm{H}$, Tsukarhara $\mathrm{S}$. The pattern electroretinogram in glaucoma: an evaluation by relative amplitude from the Bjerrum area. Br J Ophthalmol. 1989;73:131-135.

16. Pfeifer N, Bach $M$. The pattern electroretinogram in glaucoma and ocular hypertension: a cross sectional and longitudinal study. Ger J Ophthalmol. 1992;1:35-40.

17. Ruben ST, Arden GB, O'Sullivan F, et al. Pattern electroretinogram and peripheral colour contrast thresholds in ocular hypertension and glaucoma: comparison and correlation of results. $\mathrm{Br} \mathrm{J} \mathrm{Oph-}$ thalmol. 1995;79:326-331.

18. Hood DC, Xu L, Thienprasiddhi P, Greenstein VC, et al. The pattern electroretinogram in glaucoma patients with confirmed visual field deficits. Invest Ophthalmol Vis Sci. 2005;46:24112418.

19. Neoh C, Kaye SB, Brown M, et al. Pattern electroretinogram and automated perimetry in patients with glaucoma and ocular hypertension. BrJ Ophthalmol. 1994;78:359-362.

20. Graham SL, Wong VA, Drance SM, et al. Pattern electroretinograms from hemifields in normal subjects and patients with glaucoma. Invest Ophthalmol Vis Sci. 1994;35:3347-3356.

21. Bach M, Sullima F, Gerling J. Little correlation of the pattern electroretinogram (PERG) and visual field measures in early glaucoma. Doc Ophthalmol. 1998;94:253-263.

22. Salgerello T, Colotto A, Falsini B, et al. Correlation of pattern electroretinogram with optic disc cup shape in ocular hypertension. Invest Ophthalmol Vis Sci. 1999;40:1989-1997.

23. Parisi V, Manni G, Centofanti M, et al. Correlation between optical coherence tomography, pattern electroretinogram, and visual evoked potentials in open-angle glaucoma patients. Ophthalmology. 2001;108:905-912.

24. Holder GE. The pattern electroretinogram. In: Fishman GA, Birch DG, Holder GE, Brigell MG, eds. Electrophysiological Testing in Disorders of the Retina, Optic Nerve, and Visual Pathway. 2nd ed. San Francisco, CA: The Foundation of the American Academy of Ophthalmology; 2002:197-234.

25 . Korth $\mathrm{M}$. The value of electrophysiological testing in glaucomatous diseases. J Glaucoma. 1997;6:331-343.

26. Trick GL. The pattern electroretinogram in glaucoma and ocular hypertension. In: Heckenlively JR, Arden GB, eds. Principles and Practice of Clinical Electro-physiology of Vision. St. Louis: Mosby; 1991;766-772.

27. Bach M, Hoffmann MB. Update on the pattern electroretinogram in glaucoma. Optom Vis Sci. 2008;85:386-395.

28. Viswanathan S, Frishman LJ, Robson JG, et al. The photopic negative response of the macaque electroretinogram: reduction by experimental glaucoma. Invest Ophthalmol Vis Sci. 1999;40(6): $1124-1136$

29. Viswanathan S, Frishman LJ, Robson JG, et al. The photopic negative response of the flash electroretinogram in primary open angle glaucoma. Invest Ophthalmol Vis Sci. 2001;42:514-522.

30. Collotto A, Benedetto F, Salgarello T, et al. Photopic negative response of the human ERG: losses associated with glaucomatous damage. Invest Ophthalmol Vis Sci. 2000;41:2205-2211.

31. Drasdo N, Aldebasi YH, Chiti Z, et al. The S-cone PhNR and pattern ERG in primary open angle glaucoma. Invest Ophthalmol Vis Sci. 2001; $42: 1266-1272$.

32. Aldebasi YH, Drasdo N, Morgan JE, et al. S-cone, $\mathrm{L}+\mathrm{M}$ cone and pattern electroretinograms in ocular hypertension and glaucoma. Vision Res. 2004;44:2749-2756.
33. Heron G, Adams AJ, Husted R. Central fields for short wavelength sensitive pathways in glaucoma and ocular hypertension. Invest Ophthalmol Vis Sci. 1988;29:64-72.

34. Greenstein VC, Hood DC, Ritch R, et al. S (blue) cone pathway vulnerability in retinitis pigmentosa, diabetes and glaucoma. Invest Ophthalmol Vis Sci. 1989;30:1732-1737.

35. Johnson CA. Diagnostic value of shortwave automated perimetry. Curr Opin Ophthalmol. 1996;7:54-58.

36. Korth M, Nguyen NX, Junemann A, et al. VEP test of the bluesensitive pathway in glaucoma. Invest Ophthalmol Vis Sci. 1994; 35:2599-2610.

37. Jonas JB, Budd WM, Panda-Jones S. Ophthalmoscopic evaluation of the optic nerve head. Surv Ophthalmol. 1999 43(4):293-320.

38. Weinreb RN, Lusky M, Batsch DW, Morssman D. The effect of repetitive imaging on topographic measurements of the optic nerve head. Arch Ophthalmol. 1993;111:636-638

39. Schuman JS, Hee MR, Arya AV, et al. Optical coherence tomography: a new tool for glaucoma diagnosis. Curr Opin Ophthalmol. 1995;6:89-95.

40. Bach M, Pfeiffer N, Birkner-Binder D. Pattern electroretinogram reflects diffuse damage in early glaucoma. Clin Vis Sci. 1992;7: 335-340.

41. Lei Y, Garrahan N, Hermann B, et al. Quantification of retinal transneuronal degeneration in human glaucoma: a novel multiphoton-DAPI approach. Invest Ophthalmol Vis Sci. 2008;49:19401945.

42. Dichtl A, Jonas JB, Naumann GOH. Retinal nerve fiber layer thickness in human eyes. Graefes Arch Clin Exp Ophthalmol. 1999; 237:474-479.

43. Varma R, Skaf M, Barron E. Retinal nerve fibre layer thickness in normal human eyes. Ophthalmology. 1996;103:2114-2119.

44. Jones AL, Sheen NJ, North RV, et al. The Humphrey optical coherence tomography scanner: quantitative analysis and reproducibility study of the normal human retinal nerve fibre layer. $\mathrm{BrJ}$ Ophthalmol. 2001;85:673-677.

45. Sanchez-Galeana CA, Bowd C, Zangwill LM, et al. Short wavelength automated perimetry results are correlated with optical coherence tomography retinal nerve fibre layer thickness measurements in glaucomatous eyes. Ophthalmology. 2004;111:1866-1872.

46. Viswanathan S, Frishman LJ, Robson JG. The uniform field and pattern ERG in macaques with experimental glaucoma: removal of spiking activity. Invest Ophthalmol Vis Sci. 2000;41:2797-2810.

47. Parisi V, Manni G, Gandolfi SA, et al. Visual function correlates with nerve fiber layer thickness in eyes affected by ocular hypertension. Invest Ophthalmol Vis Sci. 1999;40(8):1828-1833.

48. Toffoli G, Vattovanni $\mathrm{O}$, Cecchini $\mathrm{P}$, et al. Correlation between the retinal nerve fiber layer thickness and the pattern electroretinogram. Ophthalmologica. 2002;216:159-163.

49. Parisi V, Manni G, Centofanti M, et al. Correlation between optical coherence tomography, pattern electroretinogram, and visual evoked potentials in open-angle glaucoma patients. Ophthalmology. 2001;108:905-912.

50. Harwerth RS, Vilupuru AS, Rangaswamy NV, Smith EL. The relationship between nerve fiber layer and perimetry measurements. Invest Opbthalmol Vis Sci. 2007;48:763-773.

51. Falsinin B, Marangoni D, Salgarello T, et al. Structure-function relationship in ocular hypertension and glaucoma: interindividual and interocular analysis by OCT and pattern ERG. Graefes Arch Clin Exp Ophthalmol. 2008;246:1153-1162.

52. Ventura LM, Sorokac N, De Los Santos R, et al. The relationship between retinal ganglion cell function and retinal nerve fiber thickness in early glaucoma. Invest Ophthalmol Vis Sci. 2006; 47(9):3904-3911.

53. Hernandez MR. The optic nerve head in glaucoma: role of astrocytes in tissue modelling. Prog Retin Eye Res. 2000;19:297-321.

54. Povazay B, Hofer B, Hermann B, et al. Minimum distance mapping using three-dimensional optical coherence tomography for glaucoma diagnosis. J Biomed Opt. 2007;12:041204. 